TI 2015-113/VI

Tinbergen Institute Discussion Paper

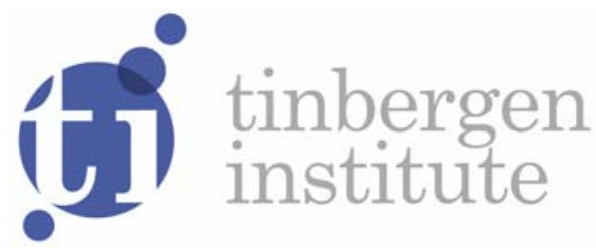

\title{
Aggregate Risk and Efficiency of Mutual Funds
}

Simas Kučinskas

Faculty of Economics and Business Administration, VU University Amsterdam, and Tinbergen Institute, the Netherlands. 
Tinbergen Institute is the graduate school and research institute in economics of Erasmus University Rotterdam, the University of Amsterdam and VU University Amsterdam.

More TI discussion papers can be downloaded at http://www.tinbergen.nl

Tinbergen Institute has two locations:

Tinbergen Institute Amsterdam

Gustav Mahlerplein 117

1082 MS Amsterdam

The Netherlands

Tel.: +31(0)20525 1600

Tinbergen Institute Rotterdam

Burg. Oudlaan 50

3062 PA Rotterdam

The Netherlands

Tel.: +31(0)10 4088900

Fax: +31(0)10 4089031 


\title{
Aggregate Risk and Efficiency of Mutual Funds
}

\author{
Simas Kučinskas* \\ VU University Amsterdam and Tinbergen Institute
}

September 23, 2015

\begin{abstract}
I analyze welfare properties of mutual funds in the Diamond-Dybvig model with two sources of aggregate risk: undiversifiable interest rate risk and shocks to aggregate liquidity demand. Mutual funds are inefficient when the economy faces undiversifiable interest rate risk. However, if only aggregate liquidity demand is stochastic, mutual funds can implement the social optimum even when liquidity demand is not directly observed.
\end{abstract}

Keywords: Mutual funds, equity contracts, liquidity creation, liquidity insurance, aggregate risk.

JEL Classification: D91, E61, G21, G23, G28.

*E-mail: s.kucinskas@vu.nl; for the latest version of the paper, visit my website. I am grateful to my advisor Björn Brügemann for his constant help and guidance. I thank seminar participants at VU University Amsterdam and Tinbergen Institute for useful comments. All mistakes are mine. 


\section{Introduction}

The global financial crisis was a stark reminder that the way financial intermediaries fund their operations can have dramatic consequences on financial markets and the real economy. Runs on financial institutions financed by short-term debt may be particularly debilitating (Brunnermeier, 2009; Duffie, 2010; Gorton and Metrick, 2012). It is therefore important to understand whether maturity mismatch and the associated rollover risk is necessary for the efficient provision of liquidity insurance, or whether there exist mechanisms that create liquidity without negative side effects on financial stability. Previous theoretical work suggests that mutual funds may be one such mechanism. The question of whether mutual funds can provide liquidity efficiently is not just of theoretical interest, as a number of recent policy proposals place mutual funds - or banks with significantly higher capital requirements - at the center of the financial system (e.g., Kotlikoff, 2010; Admati and Hellwig, 2014; Cochrane, 2014).

In this paper I analyze whether mutual funds can provide liquidity insurance efficiently in an otherwise canonical Diamond and Dybvig (1983) model with aggregate risk. As is standard, risk-averse consumers face privately observable liquidity shocks. In addition, the economy is hit by two types of aggregate shocks: undiversifiable interest rate risk and shocks to aggregate liquidity demand. The extensions to the standard model are motivated by two basic empirical observations. First, banks, being in the business of maturity transformation, are exposed to interest rate risk (e.g., Flannery and James, 1984; Hellwig, 1994; English, Van den Heuvel, and Zakrajšek, 2014; Begenau, Piazzesi, and Schneider, 2015). Second, aggregate liquidity demand varies over time and has first-order effects on the functioning of markets and intermediaries (e.g., Longstaff, 2004; Krishnamurthy, 2010; Krishnamurthy and Vissing-Jorgensen, 2012; Nagel, 2014; Krishnamurthy and Vissing-Jorgensen, 2015; Sunderam, 2015).

The current paper makes two contributions. First, I show that mutual funds are inefficient when the economy faces undiversifiable interest rate risk. The reason is that interest rate risk endogenously makes consumption in different periods imperfectly substitutable. Since the mutual fund provides liquidity insurance by driving a wedge between the private and social rates of transformation, the resulting equilibrium is inefficient. The second contribution is that shocks to aggregate liquidity demand are not detrimental for the efficiency of mutual funds. Importantly, mutual funds can implement the social optimum even if aggregate liquidity demand is not directly observed. Intuitively, when aggregate liquidity demand is high and the dividend paid by the mutual fund is constant, the price of mutual fund shares 
collapses. By increasing the dividend when the share price is low, the mutual fund can undo the negative price impact and provide first-best risk sharing.

The paper contributes to a large literature initiated by Bryant (1980) and Diamond and Dybvig (1983); for comprehensive overviews, see Gorton and Winton (2003) and Bouwman (2013). ${ }^{1}$ The work of Diamond and Dybvig provides a classic rationale for the existence of demandable debt: banks transform illiquid long-term assets into liquid short-term liabilities in order to provide liquidity insurance. Such liquidity provision, however, comes at a cost. Since the optimal funding structure is fragile, the bank is subject to self-fulfilling panics. In a seminal study, Jacklin (1987) challenged this view by showing that a dividend-paying mutual fund may be able to implement the social optimum without risking a bank run. ${ }^{2}$ Given that banks may fail to implement the social optimum because of runs, this raises the question of whether deposit-taking banks are necessary in the world envisioned by Diamond and Dybvig. In a setting without aggregate risk, Jacklin showed that mutual funds can implement the first best if consumers have the original corner preferences studied by Diamond and Dybvig. ${ }^{3}$ Jacklin noted that mutual funds are inefficient with a more general specification of preferences. In this paper, I show that mutual funds are inefficient even with the original Diamond-Dybvig preferences when the interest rate is risky. In addition, I argue that the inefficiency caused by interest rate risk may be more important than the inefficiency identified by Jacklin. For bank runs to be a Nash equilibrium in a model with smooth preferences, preferences should be close to the corner preferences originally studied by Diamond and Dybvig. In such cases, absent aggregate risk, mutual funds may lead to a negligible welfare loss. This is important from a policy perspective because, to a first approximation, run-prone banks can improve on mutual funds when returns are risky, but not otherwise.

The two most closely related papers to my work are Jacklin (1993) and Lazopoulos (2013). ${ }^{4}$ Jacklin (1993) compares mutual funds and demand deposits in a setting

\footnotetext{
${ }^{1}$ For examples of recent contributions that apply the Diamond-Dybvig framework to current policy questions, see, among others, Freixas, Martin, and Skeie (2011), Gale and Yorulmazer (2013), Allen, Carletti, and Gale (2014), and Martin, Skeie, and Von Thadden (2014).

${ }^{2}$ The mutual fund mechanism considered by Jacklin is also referred to as "equity contracts" or "market rate deposits" in the literature.

${ }^{3}$ For the implementation result of Jacklin to obtain, it is key that contracts be exclusive (i.e., no hidden trades). In Kucinskas (2015), I build on the work of Farhi, Golosov, and Tsyvinski (2009) to show that when hidden trades are possible, mutual funds are constrained efficient and therefore dominate deposit-taking banks when the probability of a bank run is non-zero.

${ }^{4}$ Hellwig (1994) analyzes a Diamond-Dybvig type model in which the return on short-term investment between period one and period two is stochastic. In that model, mutual funds are efficient (Hellwig, 1994, p. 1382). In my setup, in contrast, the short-term rate is deterministic but the rate of return on long-term investment is stochastic. Hazlett (1997) studies a Diamond-Dybvig type model with a risky long-term investment technology. The model of Hazlett is similar to mine but she does
} 
with asymmetric information about the investment return and stochastic aggregate liquidity demand. Jacklin (1993, p. 246) states (without proof) that mutual funds are efficient even when the return is risky, provided that there is no asymmetric information. ${ }^{5}$ I show that this statement is not true: when the long-term return is risky, mutual funds are no longer efficient. Lazopoulos (2013) considers a DiamondDybvig model with shocks to aggregate liquidity demand; the investment technology in his model is riskless. Lazopoulos shows that demand deposit contracts are superior to mutual funds when contracts cannot be state-contingent. Building on previous work by Jacklin (1993), I show that the exogenous restriction on the contract space is not without loss of generality. When the dividend is allowed to depend on the stock price, mutual funds can implement the full-information first best even when aggregate liquidity demand cannot be observed directly.

While both Jacklin (1993) and Lazopoulos (2013) consider the effects of aggregate risk on the efficiency of mutual funds, they do so in settings that deviate from the basic Diamond-Dybvig model (asymmetric information in the paper of Jacklin and incomplete contracts in the paper of Lazopoulos). I isolate the effects of aggregate risk by considering a benchmark model in which the only friction is private information about the liquidity shock faced by the consumers. This turns out to be important. While the previous literature suggests that it is shocks to liquidity demand, not risky investment returns, that matter for efficiency, my results show that in fact the opposite is true.

\section{Model}

I study a Diamond and Dybvig (1983) type model with a risky long-term investment technology. I first describe a model in which the level of aggregate liquidity demand is fixed. Stochastic aggregate liquidity demand is introduced in Section 4.

not consider intermediation by mutual funds.

${ }^{5}$ Jacklin writes that "As Jacklin and Bhattacharya (1988) [...] discuss, such underlying uncertainty is important only if interim information about the underlying asset returns becomes available at $T=1$. Otherwise, even if the underlying assets are risky, MRD contracts [i.e. mutual funds] can be used to achieve the socially optimal allocation.". It is not clear what part of the paper by Jacklin and Bhattacharya (1988) is alluded to in this quote. Jacklin and Bhattacharya (1988, p. 571) seem to only point out that with smooth preferences and a risky technology, mutual funds do not attain the socially efficient allocation (which coincides with the banking allocation when deposits cannot be traded, see Jacklin (1987)). The statement by Jacklin and Bhattacharya is clearly true, since aggregate risk does nothing to remove the inefficiency of mutual funds caused by smooth preferences. 


\subsection{Primitives}

Preferences and Endowments. There are three periods: $t=0,1,2$. The economy is populated by a unit measure of ex ante identical consumers. Consumers are endowed with $e$ units of an infinitely divisible consumption good at the initial date and maximize expected utility. At the beginning of period one, consumers experience a preference shock; the realization of the shock is private information. With probability $\lambda$, the consumer is an early type and only cares about consumption in period one, i.e. her utility function is given by $u\left(c_{1}\right)$. With complementary probability, the consumer is a late type. For a late type, consumption goods in period one and period two are perfect substitutes: the utility function of a late type is $u\left(c_{1}+c_{2}\right)$. Utility function $u(c)$ is twice continuously differentiable, strictly increasing, strictly concave, and satisfies Inada conditions. Finally, a law of large numbers for a continuum of i.i.d. random variables holds, so that the realized fraction of early consumers is equal to $\lambda$.

Technology. There is a single risky investment technology. The investment technology yields $R(s)$ units of consumption good in period two per one unit invested in period zero for all states of nature $s \in \mathcal{S}{ }^{6}{ }^{6}$ Random return $\widetilde{R}$ is characterized by a distribution function $F(R)$ with $\mathbb{E}[\widetilde{R}] \equiv \int R \mathrm{~d} F(R)>1$; I use tildes to denote random variables. A fraction of the long-term investment may be liquidated after observing the liquidity shock in period one. Liquidation is costless: for each unit of the long-term investment liquidated, agents receive one unit of the consumption good, as in the original Diamond and Dybvig setup. ${ }^{7}$

No Hidden Trades. I assume that there are no hidden trades, either because trades among consumers or consumption levels themselves are observable. This assumption is made to ensure that liquidity insurance is not arbitraged away by opportunistic consumers (Allen, 1985; Jacklin, 1987). ${ }^{8}$

\subsection{Benchmark Allocations}

I now define autarky, first-best, and second-best allocations in the present environment and describe some of their qualitative properties.

\footnotetext{
${ }^{6}$ Since consumption goods in different periods are perfect substitutes for the late types, it is without loss of generality to assume that the there is no storage technology.

${ }^{7}$ The assumption is for simplicity only. The results carry through straightforwardly to the case of more general investment technologies.

${ }^{8}$ See Allen and Gale (2004, Section 4) and Farhi, Golosov, and Tsyvinski (2009) for further discussion. In related work I analyze welfare properties of mutual funds in a setting with hidden trades and no aggregate risk (Kucinskas, 2015). The results of that paper easily generalize to the case of interest rate risk if markets for aggregate risk are complete.
} 


\subsubsection{Autarky}

In autarky, consumers have no access to financial markets or intermediaries. Since early consumers only derive utility from period one consumption, they liquidate all of their investment in period one and consume the proceeds: $c_{1 E}^{a u t}=e$. The optimal consumption profile for the late types is given by the solution to the following optimization problem.

Problem 1 (Autarky problem of the late types).

$$
\max _{c_{1 L} \in[0,1]} \mathbb{E}\left[u\left(c_{1 L}+\left(e-c_{1 L}\right) \widetilde{R}\right)\right] .
$$

Optimal consumption of the late types $c_{1 L}^{a u t}$ solves

$$
\mathbb{E}\left[u^{\prime}\left(c_{1 L}+\left(e-c_{1 L}\right) \widetilde{R}\right)(\widetilde{R}-1)\right] \geq 0
$$

with equality if $c_{1 L}^{\text {aut }}>0$. Increasing consumption in period one makes the consumption of a late agent more smooth across different states of nature. At the same time, increasing $c_{1 L}$ limits the potential for an upside gain from the long-term investment, and thereby consumption is smaller in expectation. At an interior optimum these marginal effects have to be equal.

\subsubsection{First-Best Allocation}

Suppose that liquidity shocks are verifiable. The social planner maximizes expected utility of the consumers subject to the resource constraint. The Pareto weights are equal to the population frequencies of the types.

Problem 2 (First-best allocation).

$$
\begin{gathered}
\max _{c_{1 E}, c_{1 L}, i} \lambda u\left(c_{1 E}\right)+(1-\lambda) \mathbb{E}\left[u\left(c_{1 L}+\frac{i \widetilde{R}}{1-\lambda}\right)\right] \\
\text { s.t. } \lambda c_{1 E}+(1-\lambda) c_{1 L}+i=e \\
i, c_{1 E}, c_{1 L} \geq 0 .
\end{gathered}
$$

Here $i$ is the aggregate investment in the long-term technology at the end of period one. At the optimum $\left(c_{1 E}^{F B}, c_{1 L}^{F B}, i^{F B}\right)$ solve

$$
\begin{aligned}
u^{\prime}\left(c_{1 E}\right) & =\mathbb{E}\left[u^{\prime}\left(c_{1 L}+\widetilde{c}_{2 L}\right) \widetilde{R}\right] \\
\mathbb{E}\left[u^{\prime}\left(c_{1 L}+\widetilde{c}_{2 L}\right)\right] & \leq \mathbb{E}\left[u^{\prime}\left(c_{1 L}+\widetilde{c}_{2 L}\right) \widetilde{R}\right],
\end{aligned}
$$


and the resource constraint, where $\widetilde{c}_{2 L}=i \widetilde{R} /(1-\lambda)$. The second condition holds with equality if $c_{1 L}^{F B}>0$. The first condition represents the standard inter-type trade-off between liquidity provision and investment present in the original Diamond and Dybvig model. If $c_{1 E}$ is higher, there is more insurance against idiosyncratic liquidity shocks, but less can be invested in the long-term technology. The second condition is specific to the current model with aggregate risk about the investment return. It represents the intertemporal trade-off that late types are exposed to: investing more in the risky technology makes consumption of the late types less smooth across different states of nature, although the upside potential is greater.

\subsubsection{Second-Best Allocation}

Since liquidity needs of the consumers are not observable, the solution to Problem 2 may not be implementable. By the Revelation Principle, it is without loss of generality to only consider allocations that satisfy the following incentive compatibility constraints:

$$
\begin{aligned}
c_{1 E} & \geq c_{1 L} \\
\mathbb{E}\left[u\left(c_{1 L}+\widetilde{c}_{2 L}\right)\right] & \geq u\left(c_{1 E}\right) .
\end{aligned}
$$

It is easy to show that the first best is incentive compatible under the natural assumption that the consumers are prudent (Kimball, 1990), i.e. marginal utility of consumption is convex. Convex marginal utility is satisfied by most commonly used preference specifications including power and exponential utility. ${ }^{9}$

Lemma 1. Assume that the consumers are prudent, that is, the marginal utility of consumption is convex. Then, the solution to the first-best problem (Problem 2) is incentive compatible.

Proof. In the Appendix.

In the rest of the paper, I assume that the first best is incentive compatible, using the above result as the justification for doing so.

\subsubsection{Decentralization by Competitive Banks}

Since there are no hidden trades in the model, the second-best allocation can be decentralized by a competitive banking system, as has as has been shown in seminal

\footnotetext{
${ }^{9}$ In addition, as has been known since Leland (1968), prudence is a necessary condition for precautionary savings to be positive.
} 
papers by Prescott and Townsend (1984) in an abstract setting and Allen and Gale (2004) in a model closer to the present one. ${ }^{10}$ As a result, we can compare mutual funds to competitive banks by comparing mutual funds to the second-best allocation. For the decentralization result to hold, there must be no panic-based runs in the banking economy. With panic-based runs, comparing banks and mutual funds is more difficult. If mutual funds can implement the second-best allocation, then mutual funds strictly dominate banks when the probability of a bank run is nonzero. If mutual funds cannot implement the second best, then the welfare ordering of banks and mutual funds depends on the relative size of the two inefficiencies. Banks are better at providing liquidity insurance but may suffer from runs, whereas mutual funds are run-proof but introduce a distortion in liquidity provision. Which of the two modes of intermediation is better in such a situation is ultimately a quantitative question.

\subsection{Mutual Funds}

I now describe how mutual funds can be used to provide some liquidity insurance. The exposition follows the classic work of Jacklin (1987) closely.

There is a competitive mutual fund sector with free entry. In period zero, the representative mutual fund raises capital by issuing shares to the consumers in return for their endowment. I normalize holdings of the mutual fund shares by each consumer at time zero to one. After the realization of liquidity shocks in period one, the mutual fund pays out a dividend $d \in[0, e]$ to each agent. Then, the agents trade $e x$-dividend shares between themselves at some market-clearing price $p$. Because of competition among funds and free entry, the dividend $d$ chosen by the representative fund maximizes the ex ante utility of the agents. As in Jacklin (1993), $d$ may be a function of $p$. For now, since aggregate liquidity demand is constant, it is without loss of generality to assume that $d$ is constant. I relax this assumption in Section 4. The timeline of the mutual fund mechanism is summarized in Figure 1.

I solve for the equilibrium by backwards induction. The market for shares has to clear in period one:

$$
\lambda=\frac{(1-\lambda)\left(d-c_{1 L}\right)}{p} .
$$

The left-hand side gives the aggregate supply of shares, while the right-hand side is the aggregate demand.

\footnotetext{
${ }^{10}$ In general, for banks to be efficient, markets for aggregate risk should be complete (Allen and Gale, 2004, see especially Section 6). In the present simple model, since all agents are identical at time zero and there are no intermediary-specific shocks at time one, banks are efficient even if markets for aggregate risk are incomplete.
} 


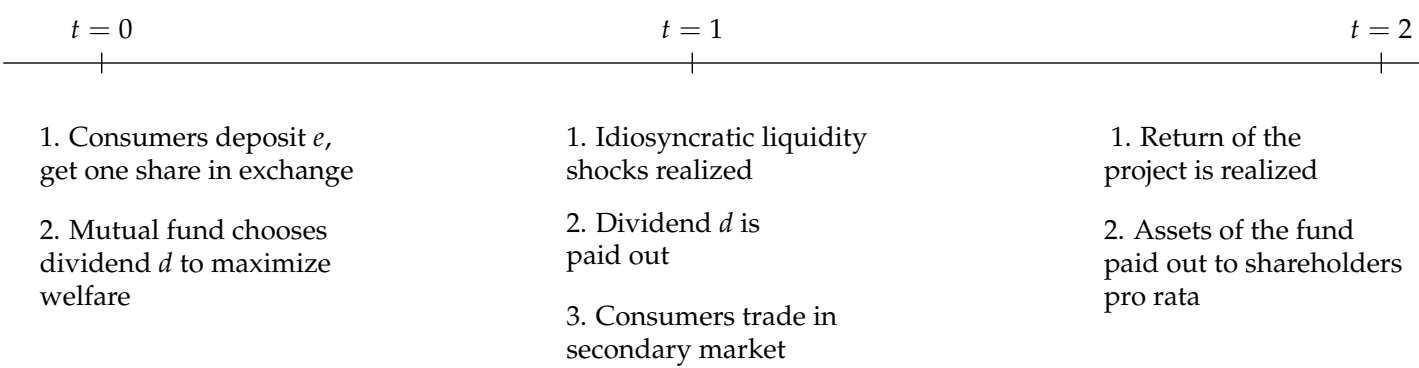

Figure 1: Timeline of the mutual fund economy.

The individual problem of the early types is very simple. They sell their shares for any price $p>0$, and consume $c_{1 E}^{M F}=d+p$. The problem of the late types is only somewhat more involved.

Problem 3 (Demand for shares).

$$
\begin{gathered}
\max _{c_{1 L}, \alpha} \mathbb{E}\left[u\left(c_{1 L}+\alpha(e-d) \widetilde{R}\right)\right] \\
\text { s.t. } c_{1 L}+\alpha p=d+p \\
c_{1 L} \geq 0 .
\end{gathered}
$$

Here $\alpha$ denotes holdings of the mutual fund shares by the late types at the end of period one. The optimal consumption at the interim date $c_{1 L}^{M F}$ solves

$$
p \mathbb{E}\left[u^{\prime}\left(c_{1 L}+\widetilde{c}_{2 L}\right)\right] \leq \mathbb{E}\left[u^{\prime}\left(c_{1 L}+\widetilde{c}_{2 L}\right) \widetilde{R}(e-d)\right],
$$

with equality if $c_{1 L}^{M F}>0$, where $\widetilde{c}_{2 L}=\widetilde{R}(e-d)\left(d+p-c_{1 L}\right) / p$.

The optimal dividend $d$ is chosen at the beginning of period zero to maximize the ex ante utility of a representative agent. As discussed above, this outcome is implied by perfect competition by mutual funds with free entry; see Kucinskas (2015) for the details. The assumption that there are no hidden trades is essential for the maximization of ex ante welfare to be an outcome of perfect competition. Let $p=p(d)$ be the price $p$ as a function of the dividend $d .{ }^{11}$ The problem of finding the optimal dividend is given below.

Problem 4 (Optimal choice of the dividend).

$$
\max _{d \in[0, e]} \lambda u(d+p(d))+(1-\lambda) \mathbb{E}\left[u\left(d+\frac{\widetilde{R}(e-d)-\lambda p(d)}{1-\lambda}\right)\right]
$$

Note that the mutual fund takes the general equilibrium effect on the share price into account when choosing the optimal dividend.

\footnotetext{
${ }^{11}$ In Appendix B I show that the equilibrium in the mutual fund economy is indeed unique under the realistic assumption that absolute risk aversion is decreasing in wealth.
} 


\section{Inefficiencies With Interest Rate Risk}

Jacklin (1987) famously pointed out that run-proof mutual funds can provide liquidity insurance efficiently when consumers have the preferences originally studied by Diamond and Dybvig. I now show that Jacklin's result depends critically on the assumption that the long-term return is deterministic. If the long-term return is risky because of, for example, macroeconomic risks, mutual funds generally cannot implement the first best.

In this section, I first derive the inefficiency result. I contrast the inefficiency caused by interest rate risk to the original implementation result of Jacklin as well as illustrate the inefficiency by means of an analytical example. Then, I show that the inefficiency result is not driven by the exogenously imposed asset structure. Finally, I argue that the inefficiency caused by aggregate risk may be more important quantitatively than the inefficiency identified by Jacklin (i.e., mutual funds are inefficient with smooth preferences).

\subsection{Inefficiency Result}

Let us now turn to the analysis of welfare properties of mutual funds when the long-term return is risky. We have the following result.

Proposition 1. If $c_{1 L}^{F B}>0$, mutual funds can implement the first-best allocation if and only if autarky and first-best allocations coincide. If $c_{1 L}^{F B}=0$ and $c_{1 E}^{F B}>e$, mutual funds can implement the first-best allocation if and only if the condition for implementation, given in Eq. (11), holds; if $c_{1 L}^{F B}=0$ and $c_{1 E}^{F B} \leq e$, the first best is always implementable.

Proof. In the Appendix.

In words, if the first-best solution is interior (i.e, $c_{1 L}^{F B}>0$ ), the mutual fund is efficient if and only if the first best coincides with autarky. In such a case, of course, there is no scope for liquidity provision to begin with, and intermediaries are redundant. Even if $c_{1 L}^{F B}=0$, the mutual fund may still fail to implement the first best if the first-best allocation involves liquidity insurance. The precise condition for implementation in such a case is given in Eq. (11).

Proposition 1 is one of the central results of this paper. Intuitively, mutual funds are inefficient because they provide liquidity insurance by driving a wedge between private and social rates of return. The intuition is given by a second-best type argument. The mutual fund economy has incomplete markets for sharing liquidity risk. If the mutual fund does not distort the rate of return, the resulting allocation coincides with autarky. The mutual fund can increase welfare by distorting the rate 
of return faced by the consumers, effectively taxing long-term investment. Since the late types invest more than the early types, distorting the rate of return has a redistributive effect. A wedge on investment therefore mitigates the welfare loss from missing markets and improves on autarky. However, if the late types are at an interior solution at the first-best allocation, the wedge between the private and social rates of return gives rise to inefficiencies as the late types react to the wedge. Even if the first-best allocation calls for no consumption by the late types at the interim date, the wedge gives the late types an incentive to increase their first period consumption in the mutual fund economy and may thereby still cause an inefficiency.

In the original Diamond-Dybvig environment, the wedge between the private and social interest rates does not lead to an inefficiency because all of the consumers are at a corner solution. To see this formally, recall that in the original Diamond and Dybvig environment, the investment project pays $R>1$ with certainty; otherwise, the model remains unchanged. In that case, a mutual fund that sets $d=\lambda c_{1 E}^{F B}$ implements the first best. The late types spend all of their income on shares as long as the return is weakly greater than one, which is the case if and only if $p \leq R(e-d)$. By the resource constraint, $c_{2 L}^{F B}=R(e-d) /(1-\lambda)$. Hence $R(e-d)=(1-\lambda) c_{2 L}^{F B}>$ $(1-\lambda) c_{1 E}^{F B}=p$ because the first-best allocation satisfies $c_{2 L}^{F B}>c_{1 E}^{F B}$. Hence we see that $p^{e q}=(1-\lambda) c_{1 E}^{F B}$ is the market-clearing price.

The results above show that the private rate of return in the original DiamondDybvig environment is

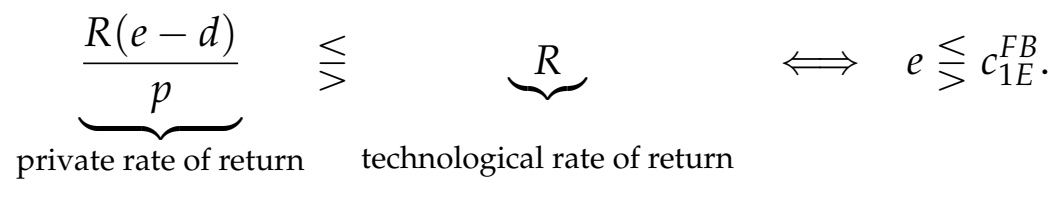

Therefore, private and social rates of return in the original Diamond-Dybvig environment are the same if and only if the first best is the same as autarky. In general, the private rate of return is distorted away from the social rate of return. Even though the late consumers face a different rate of return than the social planner, the wedge has no bearing on the efficiency of mutual funds because all consumers are at a corner solution.

\section{Example With a Closed-Form Solution}

To get further intuition, consider the following example with exponential utility and normally distributed returns. Utility is $u(c)=-\frac{1}{\rho} \exp (-\rho c)$, where $\rho$ is the coefficient of absolute risk aversion, and $\widetilde{R} \sim \mathcal{N}\left(\mu, \sigma^{2}\right)$ with $\mu>1$ and $\sigma>0$.

Let us start by working out what the first-best allocation looks like. Since the re- 
turn $\widetilde{R}$ is normally distributed and utility is exponential, $u\left(c_{1 L}+\widetilde{c}_{2 L}\right)$ is log-normally distributed, and so expected utility of the late types can be computed in closed form. ${ }^{12}$ Taking first-order conditions and performing some algebraic manipulations we get that at an interior solution ${ }^{13}$

$$
c_{1 E}^{F B}=e+\frac{(1-\lambda)(\mu-1)^{2}}{2 \rho \sigma^{2}} \text { and } c_{1 L}^{F B}=e-\left(\frac{\mu-1}{\rho \sigma^{2}}\right)\left(1+\frac{\lambda(\mu-1)}{2}\right) .
$$

A small calculation shows that aggregate consumption in period one is

$$
\lambda c_{1 E}^{F B}+(1-\lambda) c_{1 L}^{F B}=e-\frac{(1-\lambda)(\mu-1)}{\rho \sigma^{2}} .
$$

Now consider the mutual fund allocation. We work backwards. Late types in period one solve what amounts to a textbook portfolio problem. Indeed, we can interpret $c_{1 L}^{M F}$ to be holdings of a riskless one-period bond that pays zero interest, and $\alpha$ as the holdings of a risky security that pays off $\widetilde{R}(e-d)$ units of consumption good in period two. Since consumption in period one cannot be negative, the consumer is effectively facing a borrowing constraint.

Performing some algebra, we see that at an interior solution

$$
\alpha^{*}(d)=\frac{\mu(e-d)-p}{\rho \sigma^{2}(e-d)^{2}} \text { and } c_{1 L}^{*}(d)=d+p-\frac{(\mu(e-d)-p) p}{\rho \sigma^{2}(e-d)^{2}} .
$$

In equilibrium, $\alpha^{*}=1 /(1-\lambda)$. Solving for $p$ shows that at an interior equilibrium (meaning that the first-order condition of the late types in Eq. (5) holds with equality at the market clearing price)

$$
p^{e q}(d)=\mu(e-d)-\frac{\rho \sigma^{2}(e-d)^{2}}{1-\lambda} .
$$

We can now see that the mutual fund is always inefficient whenever the first best allocation is interior. Suppose the mutual fund sets $d=d^{*}$ where $d^{*}$ is the aggregate consumption at the interim date in the first-best allocation, i.e. $d^{*}=\lambda c_{1 E}^{F B}+(1-$ 1) $c_{1 L}^{F B}$. Substitute the expression for $p^{e q}\left(d^{*}\right)$ into the formula for $c_{1 L}$ in the mutual

\footnotetext{
${ }^{12}$ Since the return is normally distributed $\widetilde{c}_{2 L}$ is negative with positive probability.

${ }^{13} \mathrm{~A}$ necessary and sufficient condition for the solution to be interior is $\rho \sigma^{2} e \geq \frac{1}{2}(\mu-1)[2+$ $\lambda(\mu-1)]$, which is satisfied whenever $\rho, \sigma$ or $e$ are sufficiently big, or $\mu$ is in $(1, \bar{\mu}]$, where $\bar{\mu}=\left[\sqrt{1+2 e \lambda \rho \sigma^{2}}-(1-\lambda)\right] / \lambda$. Since $\bar{\mu}$ is strictly greater than unity, the interval for $\mu$ is not empty.
} 
fund economy to obtain that

$$
c_{1 L}^{M F}\left(d^{*}\right)-c_{1 L}^{F B}=\frac{\lambda(\mu-1)^{2}}{2 \rho \sigma^{2}} .
$$

Hence, unless $\lambda=0$ or $\mu=1$ - in which case the first best coincides with autarky — mutual funds are inefficient.

\subsection{Markets for Aggregate Risks}

Financial markets for aggregate risks are incomplete in the mutual fund economy. There is only one asset that can be traded at the interim date (mutual fund shares) but there is more than one state that can realize in period two. As a result, it is unclear whether the inefficiency result in Proposition 1 is not an artefact of the exogenous asset structure. The answer is no: with the assumed preferences, the restriction on financial assets turns out to be without loss of generality.

Let us consider the equilibrium in the mutual fund economy when trade in a full set of Arrow-Debreu securities is allowed. For simplicity, assume that the set $\mathcal{S}$ has a finite number of elements. Consumers maximize expected utility subject to the modified period one budget constraint

$$
d+p=c_{1 \theta}+\alpha_{\theta} p+\sum_{s} q(s) B_{\theta}(s)
$$

where $q(s)$ is the price of an Arrow security that pays one unit of consumption good if the state in period two is $s$ and zero otherwise, and $B_{\theta}(s)$ is the holdings of such Arrow-Debreu securities at the end of period one. In period two the following budget constraints need to be satisfied:

$$
c_{2 \theta}(s)=\alpha_{\theta}(e-d) R(s)+B_{\theta}(s) \text { for all types } \theta \text { and states } s .
$$

There is a full set of Arrow-Debreu securities that are in zero net supply. ${ }^{14}$ Market clearing conditions for the Arrow-Debreu securities are given by

$$
\lambda B_{E}(s)+(1-\lambda) B_{L}(s)=0 \text { for all states } s .
$$

As before, there is a secondary market for shares of the mutual fund.

We can now show that the restriction on the asset structure is without loss of generality.

\footnotetext{
${ }^{14}$ To rule out hidden trades, I assume that consumers can only trade Arrow-Debreu securities with other shareholders of the same mutual fund.
} 
Proposition 2. The equilibrium is unchanged by the addition of a full set of Arrow-Debreu securities.

Proof. In the Appendix.

Intuitively, the result is not unexpected. Since early types only care about consumption at the interim date, there are no obvious gains from trade in ArrowDebreu securities. The math reassures us that this indeed the case.

\subsection{Smooth Preferences}

In a setting without aggregate risk, Jacklin (1987, Theorems 2 and 3) shows that mutual funds are no longer efficient when consumers have smooth preferences (i.e., consumers derive utility from consumption in both periods). However, I now argue that the inefficiency identified by Jacklin may not always be quantitatively important. For bank runs to be an equilibrium, preferences need to be close to the ones originally analyzed by Diamond and Dybvig. Otherwise, there exists a simple bankruptcy procedure that eliminates runs altogether. When preferences are close to corner preferences, however, mutual funds may lead to a negligible welfare loss.

Before turning to the bankruptcy procedure, one must explain why it is important for runs to be be a Nash equilibrium in the first place. The answer is two-fold. From a policy perspective, banks are clearly better than mutual funds when runs are not possible. When runs are possible, mutual funds are likely to lead to a small welfare loss and hence dominate banks in a setting without aggregate risk. In contrast, with risky returns, banks may improve over mutual funds even when runs are possible. A second motivation is empirical. As discussed above, an appealing feature of the Diamond-Dybvig model is that it can jointly explain why banks exist and why they are vulnerable to runs. If the model of Jacklin is to be consistent with the observation of runs, then preferences should be close to corner preferences. ${ }^{15}$ With such preferences, the inefficiency identified by Jacklin is likely lead to a small welfare loss.

Suppose that instead of the corner preferences, utility functions are given by

$$
U\left(c_{1}, c_{2} ; \theta\right)=\rho_{\theta} \frac{c_{1}^{1-\gamma}}{1-\gamma}+\left(1-\rho_{\theta}\right) \frac{c_{2}^{1-\gamma}}{1-\gamma}, \theta \in\{E, L\}
$$

with $1>\rho_{E}>\rho_{L}>0$. As before, with probability $\lambda$, a consumer is early, and her utility function is given by $U\left(c_{1}, c_{2} ; E\right)$. With probability $1-\lambda$, her utility function is

\footnotetext{
${ }^{15}$ It is possible to change the model along other dimensions to explain runs, most prominently by introducing fundamentals-based runs as in, for example, Allen and Gale (1998).
} 
$U\left(c_{1}, c_{2} ; L\right)$. The investment technology is riskless and pays $R>1$ with probability one. The social planner maximizes ex ante utility of a representative agent subject to resource feasibility. Analytical expressions for optimal consumption levels can be found easily, but the formulas are not very enlightening and hence omitted here for brevity. The first-best allocation is always incentive compatible, and so it can be implemented by a bank that cannot observe the liquidity needs of the consumers directly (Jacklin and Bhattacharya, 1988, footnote 4). As in Diamond and Dybvig (1983), I assume that the bank is subject to a sequential service constraint.

I now claim that, for a wide class of preferences, there exists a simple mechanism that implements the first-best allocation uniquely. The mechanism does not call for suspension of payments in the event of a run. ${ }^{16}$ Essentially, the first best can often be implemented uniquely by giving seniority to the claims of the late types in the event of a bankruptcy. This possibility of ruling out runs does not arise in the original Diamond and Dybvig setup.

To that end, consider a simple numerical example. Let $\gamma=2, \rho_{I}=0.95, \rho_{P}=$ $0.05, R=1.5, \lambda=0.5$, and $e=1 .{ }^{17}$ Solving the first-order conditions shows that the optimal allocation is given by

$$
c_{1 E}^{F B} \approx 0.90, c_{1 L}^{F B} \approx 0.21, c_{2 E}^{F B} \approx 0.25, \text { and } c_{2 L}^{F B} \approx 1.10
$$

It can be verified that the allocation is incentive compatible. Assume that in period one all consumers claim to be early: there is a run on the bank. Since the allocation has $c_{1 E}^{F B}<1$, the bank can make good on all of its period one promises. However, in period two the bank can longer honour its promises: it only has $R\left(1-c_{1 E}^{F B}\right) \approx 0.16$ resources, while it has promised to pay 0.25 to everyone. Suppose, following Diamond and Dybvig, that in the second period the remaining assets are divided equally between all of the depositors. ${ }^{18}$ With this bankruptcy procedure, if everyone runs on the bank, it is a best response of a late type to also run. Thus, the original Diamond and Dybvig mechanism (absent suspension of convertibility or

\footnotetext{
${ }^{16}$ As shown by Ennis and Keister (2009), suspension of payments (also called deposit freezes) may not be a time-consistent policy.

${ }^{17}$ Note that the coefficient of relative risk aversion is greater than unity. In the original DiamondDybvig environment, this would give rise to the possibility of panic-based runs.

${ }^{18}$ The key point is that, just as in Diamond-Dybvig, there is no sequential service constraint in period two. Strictly speaking, since in the original Diamond-Dybvig environment a depositor gets paid either in period one or period two, the scenario discussed in the text cannot happen in their setup. Diamond and Dybvig (1983, p. 408) only write that "We are assuming throughout this paper that the bank is mutually owned ( " "mutual") and liquidated in period 2, so that agents not withdrawing in period 1 get a pro rata share of the bank's assets in period 2." In the scenario I consider, everyone withdraws in period one but there are still some resources left in period two. Note that if instead of being distributed equally, payments are again made sequentially in period two, then a run on the bank would still be a Nash equilibrium.
} 
possibly deposit insurance) cannot implement the first best uniquely.

However, the bank can implement the first-best allocation uniquely if it follows an alternative bankruptcy policy. Suppose that if a bank is bankrupt in period two, it first pays $c_{2 L}^{F B}$ to all agents who claimed to be late in period one. If there are not enough resources to do so, the assets are divided equally between the late types. If there are still any assets left after serving the late types, they are divided equally between the consumers who claimed to be early. Since $c_{1 E}^{F B} \leq e$, even if all consumers claim to be early, there are still enough resources to pay $c_{2 L}^{F B}$ to a late agent in period two. Since the first-best allocation is incentive compatible, this shows that truth-telling is a (strictly) dominant strategy, and hence the first-best allocation can be implemented uniquely by the bank. ${ }^{19}$

Although I used a specific example to make the point, the logic of this argument is quite general. Whenever the socially efficient allocation has $c_{1 E}^{F B} \leq e$, it is possible to use the bankruptcy procedure above to implement the first best uniquely. Therefore, if one wants to compare banks and mutual funds in a setting with bank runs, one needs to have a specification of the model that leads to $c_{1 E}^{F B}>e$. Unless the return $R$ is very high, the specification of preferences should thus be "close" to the one used by Diamond and Dybvig. By continuity, we expect mutual funds and banks to have similar welfare properties in such an environment.

\section{Shocks to Aggregate Liquidity Demand}

I now turn to the analysis of mutual funds when aggregate liquidity demand is stochastic. The key result of this section is that mutual funds can implement the full-information first best even when liquidity demand cannot be observed directly. Note that if aggregate liquidity demand is observable, the implementation problem is trivial, as we can apply the results of Jacklin (1987) state-by-state.

Instead of being fixed, the fraction of early consumers is now a random variable $\widetilde{\lambda}$ with support on $(0,1)$. To isolate the effect of stochastic liquidity demand, the investment technology is riskless with $R>1$. The social planner solves the following problem (I assume that the planner can observe the realization of the aggregate liquidity demand shock).

\footnotetext{
${ }^{19}$ See De Nicolo (1996) for a model in which a priority-of-claims provision on final date assets of the banks may be used to implement a nearly optimal allocation in a much richer environment.
} 
Problem 5 (Full-information first-best allocation).

$$
\begin{gathered}
\max _{c_{1 E}(\omega)} \lambda(\omega) u\left(c_{1 E}(\omega)\right)+(1-\lambda(\omega)) u\left(\frac{e-\lambda(\omega) c_{1 E}(\omega)}{1-\lambda(\omega)} R\right) \\
\text { s.t. } 0 \leq c_{1 E}(\omega) \leq \frac{e}{\lambda(\omega)} \text { for all states of nature } \omega \in \Omega .
\end{gathered}
$$

Since the return is fixed, I have already imposed $c_{1 L}^{F B}=0$. Since we can solve the optimization problem point-wise, we see that the optimal unique solution $c_{1 E}^{F B}(\omega)$ satisfies

$$
u^{\prime}\left(c_{1 E}(\omega)\right)=u^{\prime}\left(\frac{e-\lambda(\omega) c_{1 E}(\omega)}{1-\lambda(\omega)} R\right) R \text { for all states of nature } \omega \in \Omega .
$$

If the mutual fund can observe the aggregate demand for liquidity directly, it can easily implement the first best. This is a direct corollary of the implementation result of Jacklin (1987) that was already discussed in Section 3. Specifically, the mutual fund can implement the full-information first best by setting $d(\omega)=\lambda(\omega) c_{1 E}^{F B}(\omega)$.

Even if the mutual fund cannot observe aggregate liquidity demand directly, it may be able to infer the state of nature by observing the market-clearing price of the mutual fund shares. Jacklin (1993, Proposition 1) shows that if consumers have power utility, mutual funds can implement the first best by allowing the dividend to vary with the price of the shares in a monotone fashion. The formulation used by Jacklin does not require the mutual fund to observe the realized state. It is only necessary that the price of the shares be revealing of the state at the optimal dividend policy. ${ }^{20}$ Intuitively, if the dividend is fixed, then for a high realization $\lambda$ the price of the shares is low. There is less liquidity insurance in precisely those states of nature in which such insurance is most desired (Lazopoulos, 2013). However, if the dividend depends on the price, the mutual fund may be able to offset the price impact of a higher supply of shares.

I follow Jacklin (1993) in allowing the dividend of the mutual fund to depend on the market clearing price in a monotone way. The following proposition shows that such mutual funds can implement the social optimum whenever consumers are sufficiently risk averse, an assumption typically made in the literature. To the best of my knowledge, the result of Jacklin (1993, Proposition 1) has not been extended beyond special case of power utility. Since Jacklin proves his result by explicitly solving for the first-best and mutual fund allocations, the method of my proof is quite different.

Proposition 3. Suppose that the fraction of early consumers follows an arbitrary distribution with support on $(0,1)$, and the long-term return is fixed. Let $-u^{\prime \prime}(c) c / u^{\prime}(c)>1$ for

\footnotetext{
${ }^{20}$ Formally, the market clearing price must be a bijective function of the dividend.
} 
all $c \geq e$. If the dividend of the mutual fund can depend on the market-clearing price of the mutual fund shares, the mutual fund can implement the first-best allocation. The optimal dividend is a strictly decreasing function of the price.

Proof. In the Appendix.
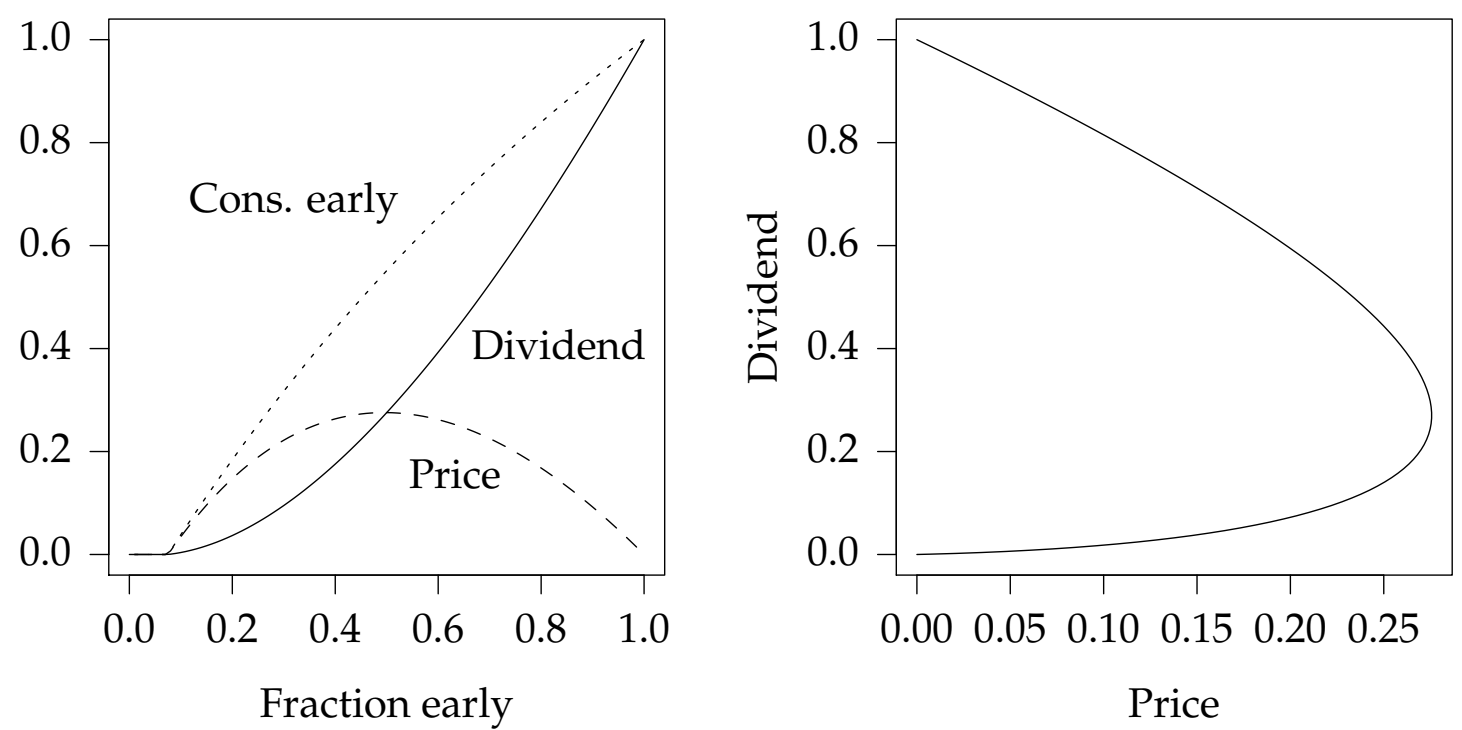

Figure 2: Left panel: Consumption of the early types, the price of shares, and the optimal dividend as a function of the fraction of early consumers $\lambda$. Right panel: market-clearing price of mutual fund shares and the optimal dividend $d^{*}=\lambda c_{1 E}(\lambda)$ as $\lambda$ varies from zero (bottom left) to one (top right). The example has $u(c)=$ $1-\exp \left(-\frac{c}{4}\right)$; endowment is $e=1$ and the long-term return is non-stochastic with $R=\frac{3}{2}$.

Intuitively, the proof uses the implicit function theorem to show that if the mutual fund sets $d(\omega)=\lambda(\omega) c_{1 E}^{F B}(\omega)$, there is a one-to-one mapping between the dividend $d(\omega)$ and the equilibrium price $p(d(\omega))$. Note that some restrictions on either the class of utility functions or distributions of $\lambda$ are necessary for mutual funds to implement the first best. Suppose that $u(c)=1-\exp (-c / 4)$ and the long-term return is non-stochastic with $R=3 / 2$. Figure 2 shows that with this specification, the market-clearing price $p$ is not monotone in $d^{*}=\lambda c_{1 E}(\lambda)$. Hence, $p^{-1}(d)$ is not defined. Non-implementability is driven by the fact that the optimal consumption of early types is increasing in $\lambda$, as shown in the left panel of Figure 2. Intuitively, when $\lambda$ is higher, two things happen. First, the optimal dividend is now higher. Since late consumers spend all of the dividend on buying shares, a higher dividend puts an upward pressure on the price. However, since $\lambda$ is higher, there is now a higher supply of shares in the market, which mechanically pushes the price down. In the example shown in Figure 2, the first effect dominates for low values 
of $\lambda$, while the second effect dominates for high values of $\lambda$. In contrast, under the assumptions of Proposition 3, the second effect dominates for all values of $\lambda$.

\section{Conclusions}

The global financial crisis was a stark reminder that the way financial intermediaries finance their operations can have important consequences for the real economy. It is therefore important to understand under what conditions banks are actually better than other means of providing liquidity insurance. In this paper, I investigated the welfare properties of mutual funds, a mechanism for providing liquidity that has received significant attention both in previous theoretical work and policy discussions. The main contribution of the paper is that, in contrast to what the previous literature suggests, it is risk about returns, not liquidity demand, that matters for the efficiency of mutual funds. Mutual funds are inefficient at providing liquidity insurance when returns are risky. If only aggregate liquidity demand is stochastic, however, mutual funds can implement the first best with a suitable dividend policy even when aggregate liquidity demand is not directly observed.

From a policy perspective, the results of the paper are useful for thinking about the current debate on the level of optimal capital requirements and the possible effects of high capital requirements on liquidity creation. This paper suggests that banks may be better than mutual funds at creating liquidity when the following conditions are met: (i) contracts are exclusive; (ii) interest rate risk is high; and (iii) the frequency of bank runs is not too high. If contracts are not exclusive, mutual funds dominate banks (Kucinskas, 2015). If there is no undiversifiable interest rate risk, mutual funds are optimal if the consumers have the original Diamond-Dybvig preferences (or have preferences that are close to the Diamond-Dybvig preferences), as shown by Jacklin (1987). Finally, the probability of bank runs should not be too high, since if runs happen too frequently, mutual funds are superior to banks, a corollary of the results in Cooper and Ross (1998). Looking forward, an important open question lies in quantifying these trade-offs and developing the implications for optimal macroprudential policy. 


\section{References}

Admati, A., Hellwig, M., 2014. The Bankers' New Clothes: What's Wrong With Banking and What to Do About It. Princeton, NJ: Princeton University Press.

Allen, F., 1985. Repeated principal-agent relationships with lending and borrowing. Economics Letters 17 (1), 27-31.

Allen, F., Carletti, E., Gale, D., 2014. Money, financial stability and efficiency. Journal of Economic Theory 149, 100-127.

Allen, F., Gale, D., 1998. Optimal financial crises. The Journal of Finance 53 (4), 1245-1284.

Allen, F., Gale, D., 2004. Financial intermediaries and markets. Econometrica 72 (4), 1023-1061.

Begenau, J., Piazzesi, M., Schneider, M., 2015. Banks' risk exposures. Working Paper, NBER.

Bouwman, C. H., 2013. Liquidity: How banks create it and how it should be regulated. In: Berger, A., Molyneux, P., Wilson, J. (Eds.), The Oxford Handbook of Banking. Oxford: Oxford University Press, pp. 184-218.

Brunnermeier, M., 2009. Deciphering the liquidity and credit crunch 2007-08. Journal of Economic Perspectives 23 (1), 77-100.

Bryant, J., 1980. A model of reserves, bank runs, and deposit insurance. Journal of Banking \& Finance 4 (4), 335-344.

Cochrane, J. H., 2014. Toward a run-free financial system. Working Paper, University of Chicago.

Cooper, R., Ross, T. W., 1998. Bank runs: Liquidity costs and investment distortions. Journal of Monetary Economics 41 (1), 27-38.

De Nicolo, G., 1996. Run-proof banking without suspension or deposit insurance. Journal of Monetary Economics 38 (2), 377-390.

Diamond, D. W., Dybvig, P. H., 1983. Bank runs, deposit insurance, and liquidity. Journal of Political Economy 91 (3), 401-419.

Duffie, D., 2010. The failure mechanics of dealer banks. Journal of Economic Perspectives $24(1), 51-72$. 
English, W. B., Van den Heuvel, S. J., Zakrajšek, E., 2014. Interest rate risk and bank equity valuations. Working Paper, Federal Reserve Board.

Ennis, H. M., Keister, T., 2009. Bank runs and institutions: The perils of intervention. The American Economic Review 99 (4), 1588-1607.

Farhi, E., Golosov, M., Tsyvinski, A., 2009. A theory of liquidity and regulation of financial intermediation. The Review of Economic Studies 76 (3), 973-992.

Flannery, M. J., James, C. M., 1984. The effect of interest rate changes on the common stock returns of financial institutions. Journal of Finance 39 (4), 1141-1153.

Freixas, X., Martin, A., Skeie, D., 2011. Bank liquidity, interbank markets, and monetary policy. Review of Financial Studies 24 (8), 2656-2692.

Gale, D., Yorulmazer, T., 2013. Liquidity hoarding. Theoretical Economics 8 (2), 291324.

Gorton, G., Metrick, A., 2012. Securitized banking and the run on repo. Journal of Financial Economics 104 (3), 425-451.

Gorton, G., Winton, A., 2003. Financial intermediation. In: Constantinides, G., Harris, M., Stulz, R. (Eds.), The Handbook of the Economics of Finance: Corporate Finance. Elsevier, pp. 431-552.

Hazlett, D., 1997. Deposit insurance and regulation in a Diamond-Dybvig banking model with a risky technology. Economic Theory 9 (3), 453-470.

Hellwig, M., 1994. Liquidity provision, banking, and the allocation of interest rate risk. European Economic Review 38 (7), 1363-1389.

Jacklin, C. J., 1987. Demand deposits, trading restrictions and risk sharing. In: Prescott, E. D., Wallace, N. (Eds.), Contractual Arrangements for Intertemporal Trade. Minnesota: University of Minnesota Press, pp. 26-47.

Jacklin, C. J., 1993. Market rate versus fixed rate demand deposits. Journal of Monetary Economics 32 (2), 237-258.

Jacklin, C. J., Bhattacharya, S., 1988. Distinguishing panics and information-based bank runs: Welfare and policy implications. The Journal of Political Economy 96 (3), 568-592.

Kimball, M. S., 1990. Precautionary saving in the small and in the large. Econometrica $58(1), 53-73$. 
Kotlikoff, L. J., 2010. Jimmy Stewart is Dead: Ending the World's Ongoing Financial Plague with Limited Purpose Banking. New Jersey: John Wiley \& Sons.

Krishnamurthy, A., 2010. How debt markets have malfunctioned in the crisis. Journal of Economic Perspectives 24 (1), 3-28.

Krishnamurthy, A., Vissing-Jorgensen, A., 2012. The aggregate demand for treasury debt. Journal of Political Economy 120 (2), 233-267.

Krishnamurthy, A., Vissing-Jorgensen, A., 2015. The impact of Treasury supply on financial sector lending and stability. Journal of Financial Economics, forthcoming.

Kucinskas, S., 2015. Liquidity creation without banks. Working Paper, VU University Amsterdam.

Lazopoulos, I., 2013. Liquidity uncertainty and intermediation. Journal of Banking \& Finance 37 (2), 403-414.

Leland, H. E., 1968. Saving and uncertainty: The precautionary demand for saving. The Quarterly Journal of Economics 82 (3), 465-473.

Longstaff, F. A., 2004. The flight-to-liquidity premium in US treasury bond prices*. The Journal of Business 77 (3), 511-526.

Martin, A., Skeie, D., Von Thadden, E.-L., 2014. Repo runs. Review of Financial Studies 27 (4), 957-989.

Nagel, S., 2014. The liquidity premium of near-money assets. Working Paper, NBER.

Prescott, E. C., Townsend, R. M., 1984. Pareto optima and competitive equilibria with adverse selection and moral hazard. Econometrica 52 (1), 21-45.

Sunderam, A., 2015. Money creation and the shadow banking system. Review of Financial Studies, forthcoming.

Wakker, P. P., 2010. Prospect Theory: For Risk and Ambiguity. Cambridge: Cambridge University Press. 


\section{Appendix A Proofs}

\section{Proof of Lemma 1}

The proof is by applying Jensen's inequality twice. Suppose that the incentive compatibility constraint does not hold for the late types at the first best, i.e. $u\left(c_{1 E}^{F B}\right)>$ $\mathbb{E}\left[u\left(c_{1 L}^{F B}+\widetilde{c}_{2 L}^{F B}\right)\right]$. This implies that

$$
c_{1 E}^{F B}>u^{-1}\left(\mathbb{E}\left[u\left(c_{1 L}^{F B}+\widetilde{c}_{2 L}^{F B}\right)\right]\right)>c_{1 L}^{F B}+\mathbb{E}\left[\widetilde{c}_{2 L}^{F B}\right],
$$

where I used Jensen's Inequality and the fact that $u^{-1}(\cdot)$ exists, is strictly increasing and strictly concave. But since $u^{\prime}$ is strictly decreasing and convex,

$$
u^{\prime}\left(c_{1 E}^{F B}\right)<u^{\prime}\left(c_{1 L}^{F B}+\mathbb{E}\left[\widetilde{c}_{2 L}^{F B}\right]\right) \leq \mathbb{E}\left[u^{\prime}\left(c_{1 L}^{F B}+\widetilde{c}_{2 L}^{F B}\right)\right]
$$

where I used Jensen's inequality in the second step. However, from Eq. (1) and Eq. (2) we have that

$$
u^{\prime}\left(c_{1 E}^{F B}\right) \geq \mathbb{E}\left[u^{\prime}\left(c_{1 L}^{F B}+\widetilde{c}_{2 L}^{F B}\right)\right],
$$

a contradiction. Hence, the incentive constraint must be satisfied for the late types. If the incentive-compatibility constraint does not hold for the early types, i.e. $c_{1 L}^{F B}>$ $c_{1 E}^{F B}$, then we immediately get a contradiction to Eq. (10).

\section{Proof of Proposition 1}

I consider two cases. First, I look at the case of an interior solution, meaning that the non-negativity constraint on $c_{1 L}^{F B}$ is not binding at the first-best solution. Then, I consider the case when $c_{1 L}^{F B}$ is zero.

Interior solution: $c_{1 L}^{F B}>0$. Suppose, for contradiction, that the mutual fund and first-best allocations are identical at some appropriately chosen dividend. Then, first-order conditions in Eq. (2) and Eq. (5) imply that $d=e-p$. Now by the budget constraint of the early types, $c_{1 E}^{M F}=d+p$. As a result, for the mutual fund and first-best allocations to coincide it is necessary to have $c_{1 E}^{F B}=e$. In that case, the first-best allocation equals autarky.

For the other direction, suppose that the first-best and autarky allocations are the same. Let the mutual fund set $d=\lambda e+(1-\lambda) c_{1 L}^{M F}$. Then, the market clearing price is $p=(1-\lambda)\left(e-c_{1 L}^{M F}\right)$ and therefore $d+p=e$. Therefore, $c_{1 E}^{M F}=e$ and, in addition, the solutions to Problem 1 and Problem 3 are the same. Thus, the mutual fund implements the first best. 
Non-interior solution: $c_{1 L}^{F B}=0$. Let $c^{*}$ denote the solution to

$$
u^{\prime}\left(c^{*}\right)=\mathbb{E}\left[u^{\prime}\left(\frac{e-\lambda c^{*}}{1-\lambda} \widetilde{R}\right) \widetilde{R}\right]
$$

A small calculation shows that $c_{1 L}^{F B}=0$ if and only if

$$
\mathbb{E}\left[u^{\prime}\left(\frac{e-\lambda c^{*}}{1-\lambda} \widetilde{R}\right)(1-\widetilde{R})\right] \leq 0 .
$$

Turning to the mutual fund allocation, a necessary and sufficient condition to implement $c_{1 L}^{F B}=0$ is given by

$$
\mathbb{E}\left[u^{\prime}\left(\frac{e-\lambda c_{1 E}^{F B}}{1-\lambda} \widetilde{R}\right)\left(1-\frac{\widetilde{R}\left(e-\lambda c_{1 E}^{F B}\right)}{(1-\lambda) c_{1 E}^{F B}}\right)\right] \leq 0
$$

It is evident that even if $c_{1 L}^{F B}=0$, the implementability condition in Eq. (11) may fail to hold if the first-best allocation involves liquidity insurance $\left(c_{1 E}^{F B}>e\right)$. If $c_{1 L}^{F B}=0$ and $c_{1 E}^{F B} \leq e$, the mutual fund can always implement the first best.

\section{Proof of Proposition 2}

Since early types derive no utility from period two consumption, we know that $c_{2 E}(s)=0$ for all states $s$. Multiply both sides of the second period budget constraint in Eq. (7) by $q(s)$, and sum get $\alpha_{E} \sum_{s} q(s) R(s)(e-d)=-\sum_{s} q(s) B_{E}(s)$. By no arbitrage, $p=\sum_{s} q(s) R(s)(e-d)$, and so $\alpha_{E} p+\sum_{s} q(s) B_{E}(s)=0$. Thus, the first period budget constraint of the early types in Eq. (6) implies that $c_{1 E}=d+p$.

Now multiply the market clearing condition in Eq. (8) by $q(s)$, and sum over $s$ to get $\lambda \sum_{s} q(s) B_{E}(s)+(1-\lambda) \sum_{s} q(s) B_{L}(s)=0$. Market clearing for the shares in Eq. (4) implies that $\lambda \alpha_{E} p+(1-\lambda) \alpha_{L} p=p$. Adding up the two equations and using the fact that $\alpha_{E} p+\sum_{s} q(s) B_{E}(s)=0$, yields $\sum_{s} q(s) B_{L}(s)=p\left(1 /(1-\lambda)-\alpha_{L}\right)$. Thus, period one budget constraint for the late types shows that $c_{1 L}=d-\lambda p /(1-\lambda)$. It remains to be shown that $B_{L}(s)+R(s)(e-d) \alpha_{L}=R(s)(e-d) /(1-\lambda)$. To do so, multiply the second period budget constraint by $\pi(\theta)$, sum over $\theta$ and use market clearing and $c_{2 E}(s)=0$ to obtain $c_{2 L}(s)=R(s)(e-d) /(1-\lambda)$, which is the obtain the desired result. Combining the facts above we see that in equilibrium $c_{1 E}=$ $d+p, c_{1 L}+c_{2 L}(s)=d-\lambda p /(1-\lambda)+R(s)(1-d) /(1-\lambda)$, and $p=(1-\lambda)(d-$ $\left.c_{1 L}\right) / \lambda$. Hence, the equilibrium is unchanged by the addition of Arrow-Debreu securities. 


\section{Proof of Proposition 3}

An application of the implicit function theorem shows that $c_{1 E}(\lambda)$ is a continuously differentiable function for all $\lambda \in(0,1)$ with

$$
c_{1 E}^{\prime}(\lambda)=\frac{\left(e-c_{1 E}\right) R^{2} u^{\prime \prime}\left(c_{2 L}\right)}{(1-\lambda)\left(\lambda R^{2} u^{\prime \prime}\left(c_{2 L}\right)+(1-\lambda) u^{\prime \prime}\left(c_{1 E}\right)\right)}<0 \text { since } c_{1 E}>e^{21}
$$

where $c_{2 L}=\left(e-\lambda c_{1 E}\right) /(1-\lambda) R$. Since the market-clearing price is equal to $p(\lambda)=(1-\lambda) c_{1 E}(\lambda), p^{\prime}(\lambda)=-c_{1 E}(\lambda)+(1-\lambda) c_{1 E}^{\prime}(\lambda)<0$. Rewrite Eq. (9) as $u^{\prime}(d(\lambda) / \lambda)=u^{\prime}((e-d(\lambda)) /(1-\lambda) R) R$. Another application of the implicit function theorem shows that $d(\lambda)$ is a continuously differentiable function for all $\lambda \in(0,1)$ with

$$
d^{\prime}(\lambda)=\frac{u^{\prime \prime}\left(c_{2 L}\right) R^{2}(e-d) /(1-\lambda)^{2}+u^{\prime \prime}\left(c_{1 E}\right) d / \lambda^{2}}{u^{\prime \prime}\left(c_{1 E}\right) / \lambda+u^{\prime \prime}\left(c_{2 L}\right) R^{2} /(1-\lambda)}>0
$$

By the inverse function theorem, $\lambda(p)$ is well-defined, continuously differentiable, and strictly decreasing. Hence, we can write $d(\lambda)=d(\lambda(p)) \equiv h(p)$. Since $d(\lambda)$ is strictly increasing and $\lambda(p)$ is strictly decreasing, their composition is strictly decreasing.

\footnotetext{
${ }^{21}$ To see this, note that $-u^{\prime \prime}(c) c / u^{\prime}(c)>1$ implies that $u^{\prime}(R c) c$ is strictly decreasing in $R$ for $c \geq e$. Therefore, $u^{\prime}(c)-u^{\prime}(R e) R>u^{\prime}(c)-u^{\prime}(1 \cdot c) \cdot 1=0$.
} 


\section{Appendix B Existence and Uniqueness}

When the return is riskless, it is immediate that a competitive equilibrium in the mutual fund economy exists and is unique. Things are a bit more complicated when the return is risky. I now give a direct proof that an equilibrium always exists in the mutual fund economy. Moreover, the equilibrium is unique under the empirically plausible assumption that absolute risk aversion is decreasing in wealth (Wakker, 2010, p. 83). ${ }^{22}$ This result is important because one appealing feature of mutual funds is that they, in contrast to demand deposits, do not give rise self-fulfilling panics.

I call an equilibrium interior if the first-order condition of the late types in Eq. (5) holds with equality at the market clearing price. The equilibrium price $p$ at an interior optimum is given by the solution to $f(p)=0$ where

$$
\begin{aligned}
f(p)=p \mathbb{E}\left[u^{\prime}\left(d-\frac{\lambda}{1-\lambda} p+\frac{\widetilde{R}(e-d)}{1-\lambda}\right)\right]- \\
\mathbb{E}\left[u^{\prime}\left(d-\frac{\lambda}{1-\lambda} p+\frac{\widetilde{R}(e-d)}{1-\lambda}\right) \widetilde{R}(e-d)\right] .
\end{aligned}
$$

In what follows, the domain of $f$ is taken to be $[0,(1-\lambda) d / \lambda]$. From the market clearing condition (4), $(1-\lambda) d / \lambda$ is a trivial upper bound for the equilibrium price. Clearly, $f$ is well-defined and continuously differentiable for all $p$ in its domain. Finally, note that if $f((1-\lambda) d / \lambda)<0$, there exists an equilibrium that is not interior.

The following lemma shows that $f^{\prime}\left(p^{*}\right)>0$ at all $p^{*}$ that solve $f(p)=0$, if any such $p^{* \prime}$ s exist:

Lemma 2. Suppose that absolute risk aversion is decreasing in wealth. Let $f\left(p^{*}\right)=0$. At any such $p^{*}, f^{\prime}\left(p^{*}\right)>0$.

Proof. Denote absolute risk aversion at consumption $c$ by $\rho(c) \equiv-u^{\prime \prime}(c) / u^{\prime}(c)$. Taking the derivative gives

$$
f^{\prime}(p)=\frac{\lambda}{1-\lambda}\left(\mathbb{E}\left[u^{\prime \prime}\left(c_{1 L}+\widetilde{c}_{2 L}\right) \widetilde{R}\right](e-d)-\mathbb{E}\left[u^{\prime \prime}\left(c_{1 L}+\widetilde{c}_{2 L}\right)\right] p\right)+\mathbb{E}\left[u^{\prime}\left(c_{1 L}+\widetilde{c}_{2 L}\right)\right] .
$$

To prove the result, it is enough to show that the term in the brackets is positive at $p^{*}$. To that end, rewrite the term in the brackets as $\int \rho\left(c_{1 L}+c_{2 L}(R)\right) u^{\prime}\left(c_{1 L}+\right.$

\footnotetext{
${ }^{22}$ As is standard, absolute risk aversion is decreasing in wealth if for $c_{H} \geq c_{L}>0,-u^{\prime \prime}\left(c_{H}\right) / u^{\prime}\left(c_{H}\right) \leq$ $-u^{\prime \prime}\left(c_{L}\right) / u^{\prime}\left(c_{L}\right)$.
} 
$\left.c_{2 L}(R)\right)(p-R(e-d)) \mathrm{d} F(R)$, . Let $\bar{R} \equiv p /(e-d)$. Note that $c_{1 L}+c_{2 L}(\bar{R})=d+p$. There are two cases two consider:

- $R \leq \bar{R}$. Then, $\rho\left(c_{1 L}+c_{2 L}(R)\right) \geq \rho(d+p)$ and $p-R(e-d) \geq 0$.

- $R \geq \bar{R}$. Then, $\rho\left(c_{1 L}+c_{2 L}(R)\right) \leq \rho(d+p)$ and $p-R(e-d) \leq 0$.

In any case, we see that the product of the two terms is $\rho\left(c_{1 L}+c_{2 L}(R)\right)(p-R(e-$ $d)) \geq \rho(d+p)(p-R(e-d))$. Since $\rho(d+p)$ does not depend on $R$, we get the following estimate

$$
\begin{aligned}
& \int \rho\left(c_{1 L}+c_{2 L}(R)\right) u^{\prime}\left(c_{1 L}+c_{2 L}(R)\right)(p-R(e-d)) \mathrm{d} F(R) \geq \\
& \rho(d+p) \int u^{\prime}\left(c_{1 L}+c_{2 L}(R)\right)(p-R(e-d)) \mathrm{d} F(R) \geq 0,
\end{aligned}
$$

where we use the fact that the first-order condition of the late types in Eq. (5) holds with equality at $p^{*}$ in the last step.

An immediate corollary is the following:

Corollary. If absolute risk aversion is decreasing in wealth, there can be at most one interior equilibrium.

Now, since $f(0)<0$, there are two cases to consider given the results above.

- There is some $p^{*} \in(0,(1-\lambda) d / \lambda)$ that solves $f(p)=0$. Then, by the Corollary above we know that $f((1-\lambda) d / \lambda)>0$, which means that there is no non-interior equilibrium.

- For all $p \in[0,(1-\lambda) d / \lambda), f(p)<0$. In this case, the equilibrium has $c_{1 L}=0$. By assumption, there is no other equilibrium with $c_{1 L}>0$.

Thus, we have proved the desired result.

Proposition 4. For all $d \in(0, e)$ an equilibrium in the mutual fund economy always exists. Moreover, if absolute risk aversion is decreasing in wealth, the equilibrium is unique. 